Narendra S. Trivedi MD, Joffre Robalino MD, Ketan Shevde MD

\title{
Interpleural block: a new technique for regional anaesthesia during percutaneous nephrostomy and nephrolithotomy
}

\begin{abstract}
Interpleural block was used in four patients undergoing percutaneous nephrostomy, one of whom also underwent percutaneous nephrolithotomy. Interpleural block was achieved with the standard technique using $30 \mathrm{ml}$ of 0.5 per cen bupivacaine. All patients tolerated the procedure well and remained haemodynamically stable during the operative procedure. Mean pain relief from initiation of interpleural block was ten hours ( $S D=4.32$ ). Interpleural block was an effective method of obtaining anaesthesia for percutaneous nephrostomy and nephrolithotomy in these four patients.
\end{abstract}

Un bloc interpleural a été utilisé chez quatre patients devant subir une néphrostomie percutanée dont un a aussi subi une néphrolithotomie percutanée. Le bloc interpleural a été acquis avec une technique standard utilisant $30 \mathrm{ml}$ de 0,5 pour cent de bupivacaïne. Tous les patients ont toléré la procédure et sont restés stables hémodynamiquement durant la procédure opératoire. En moyenne le soulagement de la douleur à partir du début du bloc interpleural était de dix heures $(S D=4.32)$. Le bloc interpleural était une méthode efficace d'obtenir l'anesthésie pour une néphrostomie perculanée et une néphrolithotomie chez ces quatre patients.

\section{Key words}

ANAESTHETIC TECHNIQUES: regional, interpleural; ANAESTHETICS, LOCAL: bupivacaine; SURGERY: urological.

From the Maimonides Medical Centre, Department of Anesthesiology, 4802 Tenth Avenue, Brooklyn, New York 11219.

Address Correspondence 1o: Dr. K. Shevde.
Percutaneous nephrostomy and nephrolithotomy are procedures performed for removal of renal calculi. The procedure may be performed in two stages, the first stage in the radiology suite for percutaneous nephrostomy under fluoroscopy control and the second in the operating room to remove the stone, nephrolithotomy. At our institution, these procedures are usually performed under local anaesthesia which provides unsatisfactory pain relief in many cases. Recently, Reistad et al. ${ }^{\prime}$ have reported the use of interpleural block in adults to provide pain relief after mastectomy, cholecystectomy and renal surgery. This technique was successfully used for percutaneous nephrostomy and nephrolithotomy in the follow. ing four patients. The study was approved by Hospital Human Research Committee and informed consent was obtained from each patient.

\section{Case 1}

A 77-yr-old woman with a history of hypertension, diabetes, atherosclerotic heart disease and chronic bronchitis was diagnosed to have left and right renal calculi. Right percutaneous nephrostomy was performed under local anaesthesia in the radiology suite followed by nephrolithotomy in the operating room under general anaesthesia. Two days later the same procedure was performed on the patient's left side using interpleural block with standard monitoring (ECG, blood pressure, respiratory rate and pulse oximetry). Left interpleural block was performed with the patient in the lateral position. After skin infiltuation with one per cent lidocaine, an 18G Tuohy needle was used to enter the eighth intercostal space percutaneously in the mid-axillary line. The interpleural space was identified by negative suction of air from a well lubricated air-filled glass syringe along with respiratory movements of the plunger. Keeping the bevel of the needle pointed medially, posteriorly, and caudally, a 20G epidural catheter was inserted through the needle and fixed well to the skin. The position of the 
epidural catheter was confirmed by fluoroscopy. Thirtyfive $\mathrm{ml}$ of 0.5 per cent bupivacaine were injected through the catheter over a five-minute period and the patient was kept in the supine position. Following the interpleural block, percutaneous nephrostomy was performed in the radiology suite. The blood pressure remained stable between $140-160 \mathrm{mmHg}$ systolic and $60-70 \mathrm{mmHg}$ diastolic and the heart rate remained between $75-85$ beats per minute. The patient did not require any supplemental sedation or narcotics during the procedure.

Upon completion of the percutaneous nephrostomy, the patient was transferred to the operating room where $20 \mathrm{ml}$ of 0.5 per cent bupivacaine were injected interpleurally (two and a half hours following the initial injection) through the epidural catheter as a top-up dose over five minutes. Percutaneous nephrolithotomy was performed under haemodynamically stable conditions. The blood pressure remained stable between $130-145 \mathrm{mmHg}$ systolic and $65-75 \mathrm{mmHg}$ diastolic and heart rate measured 80-90 beats per minute throughout the second procedure. The patient received no narcotics or sedation, tolerated the procedure well, and was pain-free for $16 \mathrm{hr}$ from the initiation of interpleural block.

\section{Case 2}

A 45-yr-old hispanic man with no significant medical problems was scheduled for left percutaneous nephrostomy for renal calculi. Left interpleural block was performed in the radiology suite with standard monitoring with patient in the lateral position. Thirty $\mathrm{ml}, 0.5$ per cent bupivacaine was injected interpleurally through the epidural catheter. The blood pressure remained stable: 130 $150 \mathrm{mmHg}$ systolic and $75-85 \mathrm{mmHg}$ diastolic as did heart rate at $72-82$ beats per minute. The patient remained stable during the procedure and did not require supplemental narcotics or sedatives. He tolerated the procedure well and remained pain-free for eight hours from initiation of interpleural block.

\section{Case 3}

A 72-yr-old woman with hypertension, atherosclerotic heart disease and diabetes was scheduled for percutaneous nephrostomy for renal calculi. Left interpleural block was performed in the radiology suite with standard monitoring (patient in left lateral position) with the same technique as previously described. Thirty $\mathrm{ml}, 0.5$ per cent bupivacaine was injected interpleurally through the epidural catheter. The blood pressure remained stable between 140-160 $\mathrm{mmHg}$ systolic and $85-95 \mathrm{mmHg}$ diastolic and the heart rate was $70-78$ beats per minute. The patient remained stable during the procedure and did not require any sedation or narcotics. She tolerated the procedure well and was pain-free for ten hours from initiation of interpleural block.

\section{Case 4}

A 60-yr-old hispanic man with no previous medical history was scheduled for left percutaneous nephrostomy for renal calculus. Left interpleural block was performed as previously described using $30 \mathrm{ml}$ of 0.5 per cent bupivacaine. The blood pressure remained stable between $110-130 \mathrm{mmHg}$ systolic and $65-75 \mathrm{mmHg}$ diastolic and the heart rate remained stable between $65-75$ beats per minute throughout the procedure. The patient did not require additional pain medications. Midazolam $2 \mathrm{mg}$, in divided doses, was given for sedation for the duration of the procedure. The patient tolerated the procedure well and remained painfree six hours from initiation of interpleural block.

\section{Discussion}

Percutaneous nephrostomy and nephrolithotomy are technically difficult and painful procedures and are sometimes performed on patients with cardio-respiratory disease, which makes the anaesthetic management more challenging. Reistad et al.' reported interpleural block as a safe and effective method for controlling pain over several dermatomes of the hemithorax.

Following this report, interpleural block has been demonstrated to be effective in pain control caused by multiple rib fractures, ${ }^{5}$ pancreatic disease ${ }^{6}$ and after thoracotomy. ${ }^{7}$ Interpleural block has also been shown to provide adequate anaesthesia for procedures such as needle localization and biopsy of breast masses, ${ }^{8}$ extracorporeal shock wave lithotripsy ${ }^{9}$ and percutaneous hepatobiliary drainage. ${ }^{10}$

While the action of interpleural block with bupivacaine is not fully understood, it has been suggested that diffusion of the local anaesthetic solution through the parietal pleura and innermost intercostal muscles causes blockade of multiple intercostal nerves to provide adequate anaesthesia. ${ }^{4}$ Experimental studies on animal models by Vade Boncouer et al. ${ }^{11,12}$ have confirmed this hypothesis.

It has been well established, in various studies, that adequate anaesthesia of longer duration can be achieved by using a larger volume of 0.5 per cent bupivacaine. ${ }^{2,13}$ Seltzer et al. ${ }^{2}$ reported that following $30 \mathrm{ml}$ of 0.5 per cent bupivacaine injected interpleurally, plasma levels of 2.07 $(\mathrm{SD}=0.58) \mu \mathrm{g} \cdot \mathrm{ml}^{-1}$ were achieved. Jorfeldt $e t$ al. ${ }^{3}$ reported the toxic level of bupivacaine to be above 4.0 $\mu \mathrm{g} \cdot \mathrm{ml}^{-1}$. We therefore used $30 \mathrm{ml}$ of 0.5 per cent bupivacaine in our patients and achieved adequate anaes- 
thesia and prolonged postoperative analgesia with excellent haemodynamic stability.

While no patient in our study had evidence of complications, the following potential complications may occur: pneumothorax, haemothorax, empyema, systemic toxicity, intravascular injection and Horner's syndrome. We believe that pleural fibrosis, pleural infection, pneumothorax, pleural effusion, severely compromised cardiorespiratory function and sensitivity to local anaesthetic agents are contraindications to interpleural block. The use of interpleural block has not been previously described to maintain anaesthesia for percutaneous nephrostomy or for a two-stage procedure such as percutaneous nephrolithotomy. These patients had excellent pain relief during the procedure without haemodynamic alterations. Mean duration of pain relief from initiation of interpleural block was ten hours.

\section{Conclusion}

Interpleural block was a safe and effective method of obtaining anaesthesia without haemodynamic disturbance in four patients for percutaneous nephrostomy and nephrolithotomy. It is a relatively simple technique and has little risk of complications. Controlled randomized studies will be necessary to determine the advantages of this technique over other forms of anaesthesia.

\section{Acknowledgement}

The authors thank Judi Passaro and Patricia Celentano for typing the manuscript.

\section{References}

1 Reistad F, Stromskag KE. Intrapleural catheter in the management of post-op pain. Regional Anesthesia 1986; 11:89-91.

2 Seltzer JL, Larijani GE. Intrapleural bupivacaine: a kinetic and dynamic evaluation. Anesthesiology: 1987; 67: 798-800.

3 Jorfeldt $L$, Lofstrom B. The effects of local anesthetics on the central circulation and respiration in man and dogs. Acta Anaesthesiol Scand 1968; 12: 153-69.

4 Covino BG. Interpleural regional analgesia. Anesth Analg 1988; 67: 427-9.

5 Rocco A, Reistad F, Gudman J, McKay W. Intrapleural administration of local anesthetic for pain relief in patients with multiple rib fractures (preliminary report). Regional Anesthesia 1987: 12, 10-4.
6 Durrani $Z$, Winnie AP, Ikuta $P$. Interpleural catheter analgesia for pancreatic pain. Anesth Analg 1988; 67: 479-81.

7 Kambam JR, Handte RE, Flanagan J et al. Intrapleural anesthesia for post thoracotomy pain relief. Anesth Analg 1987; 66: $\mathbf{S 9 0 .}$

8 Schlesinger TM, Laurito CE, Baughman VL, Carranza $C J$. Interpleural bupivacaine for mammography during needle localization and breast biopsy. Anesth Analg 1989; 68: 394-5.

9 Stromskag KE, Steen PA. Comparison of interpleural and epidural anesthesia for extracorporeal shock wave lithotripsy. Anesth Analg 1988; 67, 1181-3.

10 Rosenblatt $M$, Robalino J, Bergman A, Shevde $K$. Pleural block: a new technique for regional anesthesia during percutaneous hepatobiliary drainage. Regional Anesthesia 1989; 14 (Supplement): 57.

11 Vade Boncouer TR, Pelligrino DA, Riegler FX, Albrech" $R F$. Interpleural bupivacaine in the dog: distribution of effect and influence of injectate volume. Anesth Analg 1989; 68: S30I

12 Riegler $F X$, Pelligrino DA, Vade Boncouer TR. An animal model of intrapleural analgesia. Anesthesiology 1988; 69: A365.

13 Rosenberg PH, Scheinin BMA, Lepantalo MJ, Lindfors $O$. Continuous intrapleural infusion of bupivacaine for analgesia after thoracotomy. Anesthesiology 1987; 67: 811-3. 